\title{
Trigonella Foenum-Graecum Seeds Lowers Postprandial Blood Glucose in Overweight and Obese Individuals
}

\author{
Sathyasurya Daniel Robert, ${ }^{1}$ Aziz Al-Safi Ismail, ${ }^{2}$ and Wan Ishak Wan Rosli ${ }^{3}$ \\ ${ }^{1}$ Dietetics Program, School of Health Sciences, Health Campus, Universiti Sains Malaysia, Kubang Kerian, \\ 16150 Kota Bharu, Kelantan, Malaysia \\ ${ }^{2}$ Department of Community Medicine, School of Medical Sciences, Health campus, Universiti Sains Malaysia, \\ Kubang Kerian, 16150 Kota Bharu, Kelantan, Malaysia \\ ${ }^{3}$ Nutrition Program, School of Health Sciences, Health Campus, Universiti Sains Malaysia, Kubang Kerian, \\ 16150 Kota Bharu, Kelantan, Malaysia
}

Correspondence should be addressed to Sathyasurya Daniel Robert; dan77in@yahoo.com

Received 14 May 2014; Revised 4 August 2014; Accepted 25 August 2014; Published 3 September 2014

Academic Editor: Pedro Moreira

Copyright (c) 2014 Sathyasurya Daniel Robert et al. This is an open access article distributed under the Creative Commons Attribution License, which permits unrestricted use, distribution, and reproduction in any medium, provided the original work is properly cited.

\begin{abstract}
This study determined the effects of fenugreek on postprandial plasma glucose (PPG) and satiety among overweight and obese individuals. Fourteen subjects were studied in the morning after overnight fasts on four separate occasions. Glycaemic responses elicited by $50 \mathrm{~g}$ carbohydrate portions of white bread and jam with or without $5.5 \mathrm{~g}$ of fenugreek and fried rice with or without $5.5 \mathrm{~g}$ fenugreek were determined over $2 \mathrm{~h}$. The primary endpoint was the incremental area under the plasma glucose response curve (IAUC). Adding fenugreek to both foods significantly reduced the IAUC compared to the food alone: white bread and jam, 180 \pm 22 versus $271 \pm 23 \mathrm{mmol} \times \mathrm{min} / \mathrm{L}(P=0.001)$; fried rice, $176 \pm 20$ versus $249 \pm 25 \mathrm{mmol} \times \mathrm{min} / \mathrm{L}(P=0.001)$. Fenugreek also significantly reduced the area under the satiety curve for white bread with jam (134 \pm 27 versus $232 \pm 33 \mathrm{~mm} \times \mathrm{hr}, P=0.01)$ and fried rice ( $280 \pm 37$ versus $379 \pm 36 \mathrm{~mm} \times \mathrm{hr}, P=0.01)$. It is concluded that fenugreek significantly decreased the PPG response and increased satiety among overweight and obese individuals.
\end{abstract}

\section{Introduction}

Excessive body weight increases the risk for many chronic diseases. In 2008, more than 1.4 billion adults worldwide were overweight and of these more than 500 million were obese [1]. By 2015 it is expected that approximately 2.3 billion adults around the world will be overweight and that at least 700 million will be obese [2]. The rising trend of obesity is evident in most countries including Malaysia, where the prevalence of overweight and obesity is about $29 \%$ and $14 \%$, respectively [3]. This obesity epidemic is mainly due to excess energy intake and decreased energy expenditure [4-6]. Hence identification of natural functional foods that could increase the satiety and control the surge in the postprandial blood glucose (PPG) may promote more effective weight management and reduce the risk of overweight or obese individuals for developing chronic metabolic diseases $[7,8]$. Trigonella foenum-graecum (fenugreek) has long been used as a cooking spice and as a traditional medicine for its therapeutic properties $[9,10]$. Preliminary animal and human trials suggest possible hypoglycemic properties of fenugreek when taken orally [11]. Thus, fenugreek may be an essential ingredient in cooking as well as for the development of novel highly satiating food products with a low glycaemic index (GI). Recent research findings indicate that frequent consumption of foods with low GI reduces the risk of developing chronic diseases [12-15]. Rice and bread are commonly consumed by the Malaysian population [16]. Therefore, incorporating fenugreek in these foods may provide health benefits. However, no prior Malaysian studies are done to determine the effect of fenugreek on glycaemic control or satiety among the overweight or obese individuals. 
TABLE 1: Composition of control and test foods.

\begin{tabular}{|c|c|c|c|c|c|c|}
\hline Food & $\begin{array}{l}\text { Portion size } \\
\text { (g) }\end{array}$ & $\begin{array}{l}\text { Protein } \\
\quad(\mathrm{g})\end{array}$ & $\begin{array}{l}\text { Fat } \\
(\mathrm{g})\end{array}$ & $\begin{array}{l}\text { Dietary fiber } \\
\text { (g) }\end{array}$ & $\begin{array}{c}\text { Available } \\
\text { carbohydrate }^{\mathrm{a}} \\
(\mathrm{g})\end{array}$ & $\begin{array}{l}\text { Energy } \\
(\mathrm{K} \cdot \mathrm{cals})\end{array}$ \\
\hline White bread and jam ${ }^{\dagger}$ & 99.3 & 7.2 & 2.2 & 1.3 & 50 & 257.3 \\
\hline $\begin{array}{l}\text { White bread and jam with } \\
\text { fenugreek }^{\ddagger}\end{array}$ & 104.8 & 8.9 & 2.6 & 3.5 & 50 & 273.7 \\
\hline Fried rice ${ }^{\dagger}$ & 62.3 & 5.2 & 5.0 & 3.6 & 50 & 254.9 \\
\hline Fried rice with fenugreek ${ }^{\ddagger}$ & 67.8 & 6.9 & 5.4 & 5.8 & 50 & 271.4 \\
\hline Fenugreek (per 5.5 g) & - & 1.7 & 0.4 & 2.2 & 0.4 & 16.4 \\
\hline
\end{tabular}

${ }^{a}$ Available carbohydrates are calculated as follows: $100-$ (moisture + protein + fat + dietary fiber + ash).

${ }^{\dagger}$ Control foods.

${ }^{\ddagger}$ Test foods.

Hence the purpose of this study was to examine the effects of untreated fenugreek seed powder on postprandial glycaemic responses and satiety in overweight and obese Malaysian individuals.

\section{Materials and Methods}

2.1. Subjects. Sixteen overweight or obese subjects $(7$ men and 9 women) aged 32-52 years were recruited through the advertisements posted in the intranet web mail of the Universiti Sains Malaysia. Subjects were excluded based on the following criteria: BMI $<25 \mathrm{~kg} / \mathrm{m}^{2}$, currently pregnant or lactating, intended or unintended weight loss of $>5 \mathrm{~kg}$ in the prior 3 months, history of binge-eating disorder, smoking or alcohol abuse, diabetes, renal or hepatic diseases, use of weight loss, lipid-lowering, antihypertensive or antiinflammatory steroid medications, and use of fiber supplements. Two subjects were eliminated during the study process because their postprandial glycaemic response was $>16.9 \mathrm{mmol} / \mathrm{L}$ (304.2 $\mathrm{mg} / \mathrm{dL})$. Hence the study was completed with 14 subjects. The Universiti Sains Malaysia Ethical Committee approved the study. All subjects gave written, informed consent after reviewing the study procedures. The study was conducted at the Dietetics Laboratory, School of Health Sciences, Universiti Sains Malaysia.

2.2. Control and Test Foods. Fenugreek seeds (TESCO; Kota Bharu) were heated in a microwave oven for one minute and ground in a blender. The ground seeds were sieved to obtain a fine powder which was then stored in an air tight container. Fenugreek seed powder was added to a white bread and strawberry jam sandwich by mixing $5.5 \mathrm{~g}$ powder into $15.6 \mathrm{~g}$ jam which was spread onto $83.7 \mathrm{~g}$ white bread. Fenugreek seed powder was added to fried rice as follows: $62.3 \mathrm{~g}$ white rice was cooked in a rice cooker for $25-30 \mathrm{~min}$ and transferred to a hot frying pan containing $5 \mathrm{~g}$ of oil. Chicken flavoured seasoning (8.5 g) and $5.5 \mathrm{~g}$ fenugreek seed powder were added to the rice, stirred, and sautéed for $3 \mathrm{~min}$. The nutrient composition of the test foods is shown in Table 1.

2.3. Feeding Protocol. Prior to the main study a pilot study was done with 3 subjects in order to determine the taste tolerance of fenugreek powder and its effect on the PPG response. No effect was noticed with $2 \mathrm{~g}$ of fenugreek seed powder per $50 \mathrm{~g}$ carbohydrate portion of white bread and jam. However, considerable reduction in the PPG was noted when the white bread and jam contained $5.5 \mathrm{~g}$ of fenugreek seed powder. In addition the subjects were able to tolerate the bitter taste of the fenugreek at this dose. Therefore, the main study had a crossover design in which 14 subjects participated on four separate occasions after a $10-12 \mathrm{hr}$ overnight fast when they consumed, in random order, one of the following test meals: $50 \mathrm{~g}$ carbohydrate from white bread and jam alone or with $5.5 \mathrm{~g}$ fenugreek seed powder or $50 \mathrm{~g}$ carbohydrate from fried rice alone or with $5.5 \mathrm{~g}$ fenugreek seed powder. All subjects underwent 4 tests on separate mornings with at least 10 to 15 days between successive testing sessions. On each incident subjects gave a fasting blood sample and then consumed one of the 4 study meals within 10 to 13 minutes; further blood samples were collected at 15, 30, 45, 60, 90, and 120 minutes after starting to eat. Study meals were served with $250 \mathrm{~mL}$ of water. Capillary finger-prick blood samples (11 drops) were collected into $1.5 \mathrm{~mL}$ eppendorf tubes containing fluoride oxalate and centrifuged to obtain plasma, which was stored at $-20^{\circ} \mathrm{C}$ prior to analysis. Plasma glucose was measured by using a Randox glucose GOD/PAP autoanalyzer which uses the glucose oxidase method. All subjects were asked to complete a satiety score sheet before consuming each test meal and after every blood sample thereafter for $2 \mathrm{~h}$ using a 6-point scale on which 0 was "extremely hungry" and 6 was "extremely full" [17]. Upon completion of the test meals, subjects rated the palatability on a Likert scale on which a score of 1 was "strongly dislike," 2 was "dislike," 3 was "neutral," 4 was "like", and 5 was "strongly like" [18].

2.4. Statistical Analysis. Data analysis was conducted using Microsoft Excel Spreadsheets and Graph Pad Prism version 5 (GraphPad Software, San Diego, CA, USA). The IAUC values and satiety scores were subjected to repeated measures ANOVA and, after demonstrating significant heterogeneity, the least significant differences between individual means were obtained by Bonferroni multiple comparisons. A value of $P<0.05$ was considered significant. Results are expressed as means \pm SEM. 


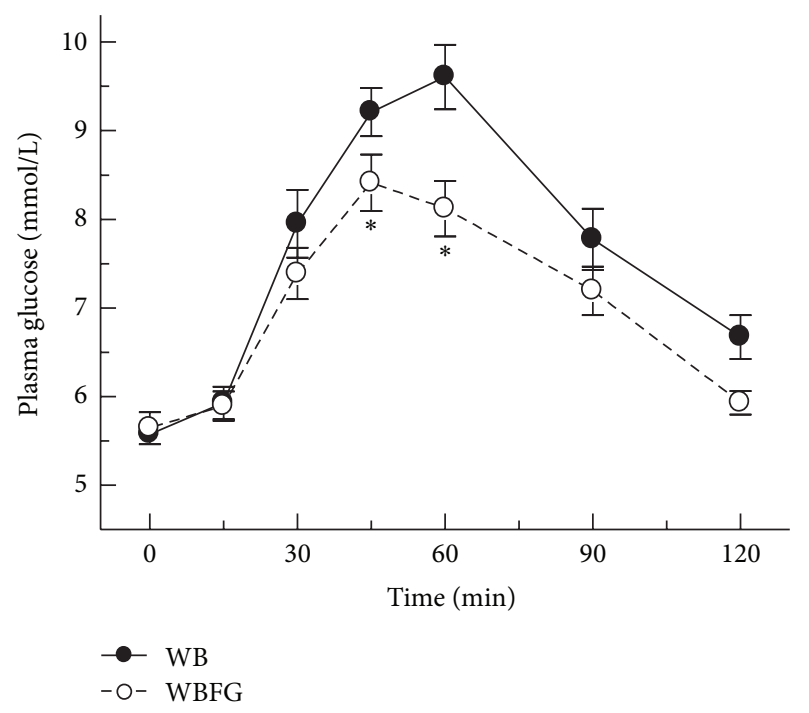

(a)

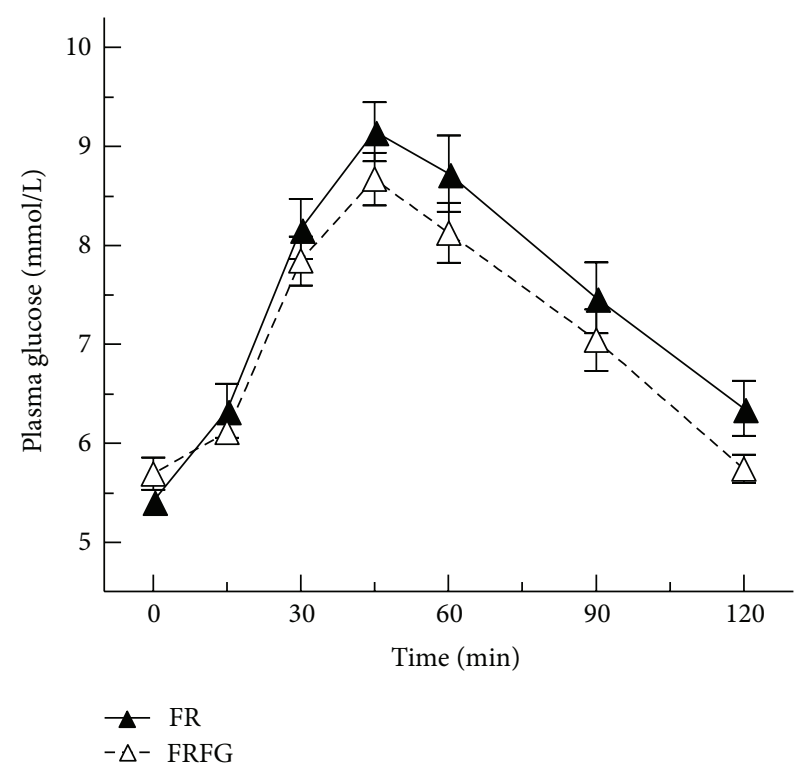

(b)

Figure 1: (a) Mean plasma glucose response of white bread and white bread with fenugreek. Values are means \pm SEM $(n=14)$. Comparison of plasma glucose concentrations $\left({ }^{*} P<0.05\right)$. WB: white bread; WBFR: white bread with fenugreek. (b) Mean plasma glucose response of fried rice and fried rice with fenugreek. Values are means \pm SEM $(n=14)$. Comparison of plasma glucose concentrations. FR: fried rice; FRFG: fried rice with fenugreek.

\section{Results}

The 14 subjects (7 women and 7 men) who completed the study were aged $38.6 \pm 1.4$ years and had a BMI of $29.9 \pm$ $1.3 \mathrm{~kg} / \mathrm{m}^{2}$. Among the subjects $28.6 \%$ ( 3 men and 1 woman) were obese and the rest were overweight. Their mean systolic blood pressure was $122.6 \pm 3.1 \mathrm{~mm} \mathrm{Hg}$ and diastolic blood pressure was $78 \pm 1.7 \mathrm{~mm} \mathrm{Hg}$.

3.1. Blood Glucose Responses. Plasma glucose after consuming white bread with fenugreek was significantly lower at $45 \mathrm{~min}$ and $60 \mathrm{~min}$ when compared to white bread alone (Figure 1(a)). Plasma glucose after fried rice with fenugreek tended to be lower at $45 \mathrm{~min}$ and $60 \mathrm{~min}$ when compared to fried rice alone but the difference was not statistically significant (Figure 1(b)). However, significant differences were seen in IAUC between the control and fenugreek-enriched foods for both bread and rice $(P=0.001)$ (Table 2).

3.2. Satiety and Taste. The satiety incremental area under the curve (SIAUC) of both test foods was significantly higher than the SIAUC of the control foods $(P=0.01)$ (Table 2). Palatability ratings of white bread with fenugreek showed that $57.1 \%$ of the subjects choose the option dislike, $28.6 \%$ choose neutral, and $14.3 \%$ choose like. Whereas the palatability ratings of fried rice with fenugreek revealed that $14.3 \%$ of the subjects choose the option dislike, $21.4 \%$ choose neutral, and $64.3 \%$ choose like. Paired $t$-test showed that there were no statistical differences in palatability score between the 2 test foods, $P=1.0$.
TABLE 2: Incremental area under the curve and satiety area under the curve of test foods and control foods.

\begin{tabular}{lcc}
\hline Foods & $\begin{array}{c}\text { Area under } \\
\text { the curve } \\
(\mathrm{mmol} \times \mathrm{min} / \mathrm{L})\end{array}$ & $\begin{array}{c}\text { Satiety area } \\
\text { under the curve } \\
(\mathrm{mm} \times \mathrm{hr})\end{array}$ \\
\hline $\begin{array}{l}\text { White bread and jam } \\
\dagger\end{array}$ & $271 \pm 23$ & $134 \pm 27$ \\
$\begin{array}{l}\text { White bread and jam with } \\
\text { fenugreek }^{\ddagger}\end{array}$ & $180 \pm 22^{*}$ & $232 \pm 33^{*}$ \\
Fried rice $^{\dagger}$ & $249 \pm 25$ & $280 \pm 37$ \\
Fried rice with fenugreek $^{\ddagger}$ & $176 \pm 20^{*}$ & $379 \pm 36^{*}$ \\
\hline
\end{tabular}

Mean \pm SEM

${ }^{*}$ Mean values within a column are significantly different from the respective control foods $(P<0.05)$.

${ }^{\dagger}$ Control foods.

${ }^{\ddagger}$ Test foods.

\section{Discussion}

This crossover study demonstrated that incorporation of natural fenugreek seed powder to the test foods lowered the surge in PPG response and increased satiety in overweight and obese subjects. It was noted that there was a reduction of $14.4 \mathrm{mg} / \mathrm{dL}$ (PPG) at $45 \mathrm{~min}$ and a reduction of $27 \mathrm{mg} / \mathrm{dL}$ (PPG) at $60 \mathrm{~min}$ after the consumption of white bread with fenugreek, when compared with that of the control food. On the other hand, it was noted that after the consumption of fried rice with fenugreek the PPG decreased by $10.8 \mathrm{mg} / \mathrm{dL}$ at $60 \mathrm{~min}$, when compared to the control food, but it was not significantly lower. A previous study by Mathern et al. found no reductions in PPG in response 
to a beverage supplemented with $8 \mathrm{~g}$ of isolated fenugreek fiber among obese subjects [19]. In another study, Sharma and Raghuram found that $100 \mathrm{~g}$ of defatted fenugreek seed powder, when given for 20 days, produced a significant fall in fasting blood glucose levels and an improvement in glucose tolerance test among subjects with type 2 diabetes [20]. Results from several additional studies also suggest that fenugreek seeds may improve glycaemic control in patients with type 2 diabetes [21-24]. However, in all those studies the patients took their regular glucose lowering medications. The hypoglycemic action of fenugreek has been related to several processes. In vitro studies demonstrated that the amino acid 4-hydroxyisoleucine in fenugreek seeds increased insulin release from human and rat pancreas. This amino acid acted only on pancreatic beta cells, but the levels of other hormones such as somatostatin and glucagon were not changed [10]. Other human studies reported that fenugreek seeds increased the number of insulin receptors, thereby decreasing the postprandial area under the curve [10]. Fenugreek seeds can also exert hypoglycemic effects by inhibiting the activities of alpha-amylase and sucrase, the two intestinal enzymes that are involved in carbohydrate digestion and absorption [10]. In clinical studies the hypoglycemic action of fenugreek has been attributed to its content of galactomannan, a water soluble fiber, which inhibits glucose absorption and slows gastric emptying [25-29]. On the other hand the satiety area under the curve after the test foods was significantly higher than that after the control foods. The increase in satiety may be due to the presence of the soluble fiber galactomannan in fenugreek. Galactomannan has gel forming characteristics which reduces gastric emptying [25]. It has been reported that $8 \mathrm{~g}$ of fenugreek extract, providing $7.2 \mathrm{~g}$ total fiber $(78.9 \%$ soluble fiber), increased satiety and reduced hunger among obese subjects [19]. However, in this study we noted that addition of fenugreek seed powder to the test foods increased its total dietary fiber content by $2.18 \mathrm{~g}$, which increased satiety. Several studies have stated that protein can promote satiety [30-32]. Protein induced satiety may be due to increase in thermogenesis, increase in the concentrations of the appetite suppressing hormones such as glucagon like peptide-1, cholecystokinin, and peptide tyrosine tyrosine, and decrease in appetite stimulating hormones such as ghrelin [33-38]. In a single blinded crossover design study, it was noted that satiety was increased after the subjects consumed a higher protein lunch containing $25 \%$ of the energy as dietary protein [39]. But in this study the effect of protein on satiety may be minor, because the addition of fenugreek to the test foods increased their protein content by merely $13 \%$ (white bread) and $10.2 \%$ (rice) of the energy.

In the earlier studies, defatted or isolated or extracted fenugreek was used as experimental food [20]. In contrast, untreated fenugreek seed powder was given to the subjects of this study. Processed fenugreek seed powder or any processed functional food may not be easily available for the general public. But our study showed that untreated fenugreek (functional food) can easily be obtained from the food market and by following simple cooking methods can be added in the daily diet, which is the strength of this study. The subjects of this study were able to tolerate the taste of the fenugreek well when it was added with fried rice than when it was added with white bread and jam. This shows that the bitterness of the fenugreek can be masked when it is added to spicy foods. The limitation of this study is the bitterness of the fenugreek which may limit its daily use.

\section{Conclusion}

In conclusion, addition of $5.5 \mathrm{~g}$ of untreated fenugreek seed powder to rice or bread containing $50 \mathrm{~g}$ available carbohydrate reduced PPG responses and increased satiety in overweight and obese individuals. As obesity is a component of metabolic syndrome which eventually leads to type 2 diabetes, incorporation of fenugreek in the daily diet may assist with weight management and hence may help prevent or delay the onset of chronic diseases.

Further research can be done to measure insulin index in order to learn more about the mechanism of action. In addition novel food products enriched with fenugreek can be developed.

\section{Conflict of Interests}

The authors have no conflict of interests. The authors alone are responsible for the content and writing of the paper.

\section{Acknowledgments}

The authors thank the study participants for their cooperation and all those who helped them in conducting this study. This study was funded by Universiti Sains Malaysia Short Term Grant (304/PPSK/61312036).

\section{References}

[1] "Obesity and overweight," 2013, http://www.who.int/mediacentre/factsheets/fs311/en/index.html.

[2] D. M. Nguyen and H. B. El-Serag, "The epidemiology of obesity," Gastroenterology Clinics of North America, vol. 39, no. 1, pp. 1-7, 2010.

[3] A. Z. Khambalia and L. S. Seen, "Trends in overweight and obese adults in Malaysia (1996-2009): a systematic review," Obesity Reviews, vol. 11, no. 6, pp. 403-412, 2010.

[4] A. K. Kant and B. I. Graubard, "Secular trends in patterns of self-reported food consumption of adult Americans: NHANES 1971-1975 to NHANES 1999-2002," The American Journal of Clinical Nutrition, vol. 84, no. 5, pp. 1215-1223, 2006.

[5] A. M. Prentice and S. A. Jebb, "Obesity in britain: gluttony or sloth?” The British Medical Journal, vol. 311, no. 7002, pp. 437439, 1995.

[6] W. H. Dietz Jr. and S. L. Gortmaker, "Do we fatten our children at the television set? Obesity and television viewing in children and adolescents," Pediatrics, vol. 75, no. 5, pp. 807-812, 1985.

[7] C. M. Hasler and A. C. Brown, "Position of the American Dietetic Association: functional foods," Journal of the American Dietetic Association, vol. 109, no. 4, pp. 735-746, 2009.

[8] S. Henson, O. Masakure, and J. Cranfield, "The propensity for consumers to offset health risks through the use of functional foods and nutraceuticals: the case of lycopene," Food Quality and Preference, vol. 19, no. 4, pp. 395-406, 2008. 
[9] R. Nahas and M. Moher, "Complementary and alternative medicine for the treatment of type 2 diabetes," Canadian Family Physician, vol. 55, no. 6, pp. 591-596, 2009.

[10] E. Basch, C. Ulbricht, G. Kuo, P. Szapary, and M. Smith, "Therapeutic applications of fenugreek," Alternative Medicine Review, vol. 8, no. 1, pp. 20-27, 2003.

[11] N. Z. Baquer, P. Kumar, A. Taha, R. K. Kale, S. M. Cowsik, and P. McLean, "Metabolic and molecular action of Trigonella foenum-graecum (fenugreek) and trace metals in experimental diabetic tissues," Journal of Biosciences, vol. 36, no. 2, pp. 383396, 2011.

[12] L. Barclay and D. Lie, "High glycemic index foods may increase risk for type 2 diabetes in Chinese women," Archives of Internal Medicine, vol. 167, pp. 2310-2316, 2007.

[13] R. Villegas, S. Liu, Y. T. Gao et al., "Prospective study of dietary carbohydrates, glycemic index, glycemic load, and incidence of type 2 diabetes mellitus in middle-aged Chinese women," Archives of Internal Medicine, vol. 167, no. 21, pp. 2310-2316, 2007.

[14] P. A. Nancy and C. R. Rhymer, "Issues surrounding health claims for barley," The Journal of Nutrition, vol. 138, no. 6, pp. 1237S-1243S, 2008.

[15] A. Mente, L. De Koning, H. S. Shannon, and S. S. Anand, "A systematic review of the evidence supporting a causal link between dietary factors and coronary heart disease," Archives of Internal Medicine, vol. 169, no. 7, pp. 659-669, 2009.

[16] J. A. Howden, Y. H. Chong, S. F. Leung et al., "Breakfast practices in the Asian Region," Pacific Journal of Clinical Nutrition, vol. 2, no. 2, pp. 77-84, 1993.

[17] S. H. A. Holt, J. C. Brand Miller, P. Petocz, and E. Farmakalidis, "A satiety index of common foods," European Journal of Clinical Nutrition, vol. 49, no. 9, pp. 675-690, 1995.

[18] H. N. Boone Jr. and D. A. Boone, "Analyzing Likert data, Journal of Extension, vol. 50, no. 2, pp. 1-5, 2012.

[19] J. R. Mathern, S. K. Raatz, W. Thomas, and J. L. Slavin, "Effect of fenugreek fiber on satiety, blood glucose and insulin response and energy intake in obese subjects," Phytotherapy Research, vol. 23, no. 11, pp. 1543-1548, 2009.

[20] R. D. Sharma and T. C. Raghuram, "Hypoglycaemic effect of fenugreek seeds in non-insulin dependent diabetic subjects," Nutrition Research, vol. 10, no. 7, pp. 731-739, 1990.

[21] Z. Madar, R. Abel, S. Samish, and J. Arad, "Glucose-lowering effect of fenugreek in non-insulin dependent diabetics," European Journal of Clinical Nutrition, vol. 42, no. 1, pp. 51-54, 1988.

[22] A. Bordia, S. K. Verma, and K. C. Srivastava, "Effect of ginger (Zingiber officinale Rosc.) and fenugreek (Trigonella foenumgraecum L.) on blood lipids, blood sugar and platelet aggregation in patients with coronary artery disease," Prostaglandins Leukotrienes and Essential Fatty Acids, vol. 56, no. 5, pp. 379384, 1997.

[23] R. D. Sharma, "Effect of fenugreek seeds and leaves on blood glucose and serum insulin responses in human subjects," Nutrition Research, vol. 6, no. 12, pp. 1353-1364, 1986.

[24] R. D. Sharma, A. Sarkar, D. K. Hazra et al., "Use of fenugreek seed powder in the management of non-insulin dependent diabetes mellitus," Nutrition Research, vol. 16, no. 8, pp. 13311339, 1996.

[25] J. M. A. Hannan, L. Ali, B. Rokeya et al., "Soluble dietary fibre fraction of Trigonella foenum-graecum (fenugreek) seed improves glucose homeostasis in animal models of type 1 and type 2 diabetes by delaying carbohydrate digestion and absorption, and enhancing insulin action," The British Journal of Nutrition, vol. 97, no. 3, pp. 514-521, 2007.

[26] S. J. French and N. W. Read, "Effect of guar gum on hunger and satiety after meals of differing fat content: relationship with gastric emptying," The American Journal of Clinical Nutrition, vol. 59, no. 1, pp. 87-91, 1994.

[27] P.-H. Groop, A. Aro, S. Stenman, and L. Groop, "Long-term effects of guar gum in subjects with non-insulin-dependent diabetes mellitus," The American Journal of Clinical Nutrition, vol. 58, no. 4, pp. 513-518, 1993.

[28] P. Würsch and F. X. Pi-Sunyer, "The role of viscous soluble fiber in the metabolic control of diabetes: a review with special emphasis on cereals rich in $\beta$-glucan," Diabetes Care, vol. 20, no. 11, pp. 1774-1780, 1997.

[29] M. Chandalia, A. Garg, D. Lutjohann, K. von Bergmann, S. M. Grundy, and L. J. Brinkley, "Beneficial effects of high dietary fiber intake in patients with type 2 diabetes mellitus," The New England Journal of Medicine, vol. 342, no. 19, pp. 1392-1398, 2000.

[30] A. Astrup, "The satiating power of protein-a key to obesity prevention?" The American Journal of Clinical Nutrition, vol. 82, no. 1, pp. 1-2, 2005.

[31] E. C. Westman, W. S. Yancy, J. S. Edman, K. F. Tomlin, and C. E. Perkins, "Effect of 6-month adherence to a very low carbohydrate diet program," The American Journal of Medicine, vol. 113, no. 1, pp. 30-36, 2002.

[32] W. A. M. Blom, A. Lluch, A. Stafleu et al., "Effect of a highprotein breakfast on the postprandial ghrelin response," The American Journal of Clinical Nutrition, vol. 83, no. 2, pp. 211220, 2006.

[33] A. Raben, L. Agerholm-Larsen, A. Flint, J. J. Holst, and A. Astrup, "Meals with similar energy densities but rich in protein, fat, carbohydrate, or alcohol have different effects on energy expenditure and substrate metabolism but not on appetite and energy intake," The American Journal of Clinical Nutrition, vol. 77, no. 1, pp. 91-100, 2003.

[34] L. Tappy, "Thermic effect of food and sympathetic nervous system activity in humans," Reproduction Nutrition Development, vol. 36, pp. 391-397, 1996.

[35] B. Parker, M. Noakes, N. Luscombe, and P. Clifton, "Effect of a high-protein, high-monounsaturated fat weight loss diet on glycemic control and lipid levels in type 2 diabetes," Diabetes Care, vol. 25, no. 3, pp. 425-430, 2002.

[36] D. R. Gustafson, D. J. McMahon, J. Morrey, and R. Nan, "Appetite is not influenced by a unique milk peptide: caseinomacropeptide (CMP)," Appetite, vol. 36, no. 2, pp. 157-163, 2001.

[37] A. M. Wren, L. J. Seal, M. A. Cohen et al., "Ghrelin enhances appetite and increases food intake in humans," Journal of Clinical Endocrinology and Metabolism, vol. 86, no. 12, pp. 59925995, 2001.

[38] W. L. Hall, D. J. Millward, S. J. Long, and L. M. Morgan, "Casein and whey exert different effects on plasma amino acid profiles, gastrointestinal hormone secretion and appetite," British Journal of Nutrition, vol. 89, no. 2, pp. 239-248, 2003.

[39] A. J. Smeets, S. Soenen, N. D. Luscombe-Marsh, Ø. Ueland, and M. S. Westerterp-Plantenga, "Energy expenditure, satiety, and plasma ghrelin, glucagon-like peptide 1 , and peptide tyrosinetyrosine concentrations following a single high-protein lunch," The Journal of Nutrition, vol. 138, no. 4, pp. 698-702, 2008. 


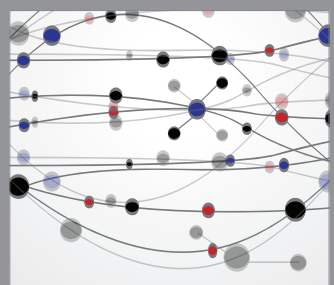

The Scientific World Journal
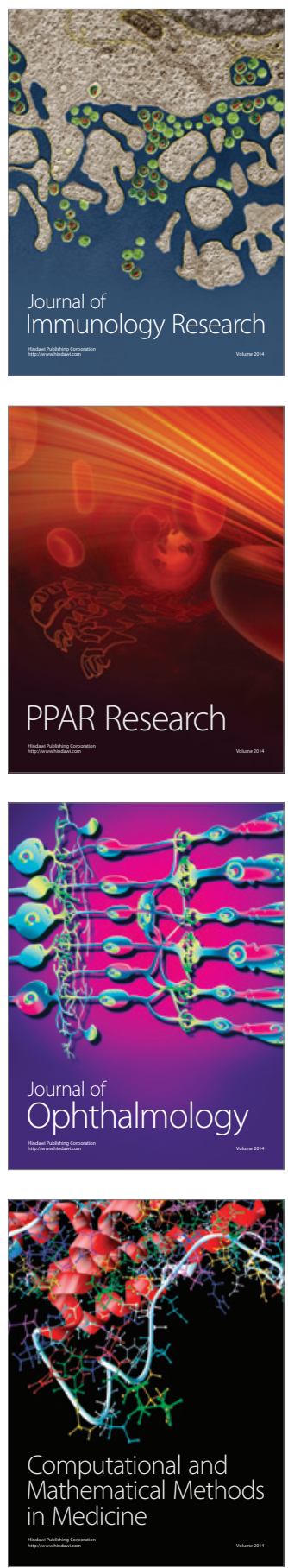

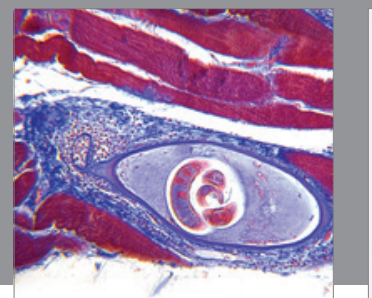

Gastroenterology

Research and Practice
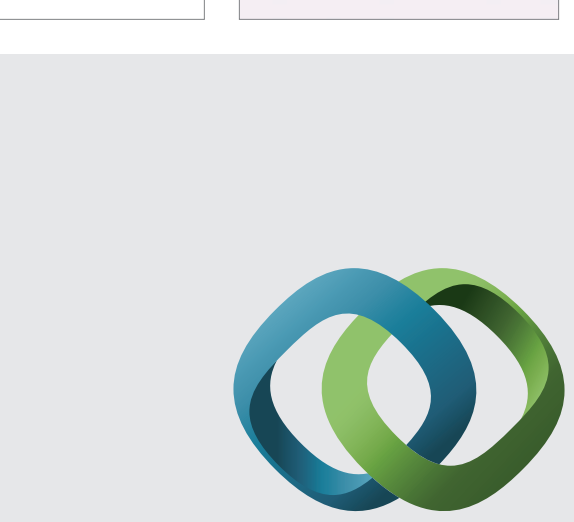

\section{Hindawi}

Submit your manuscripts at

http://www.hindawi.com
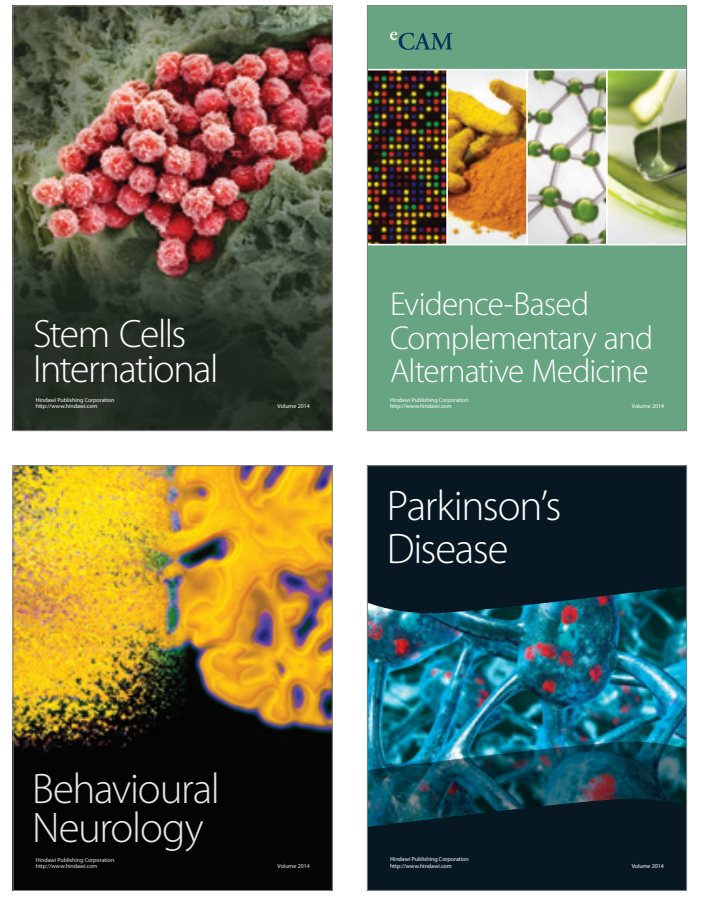
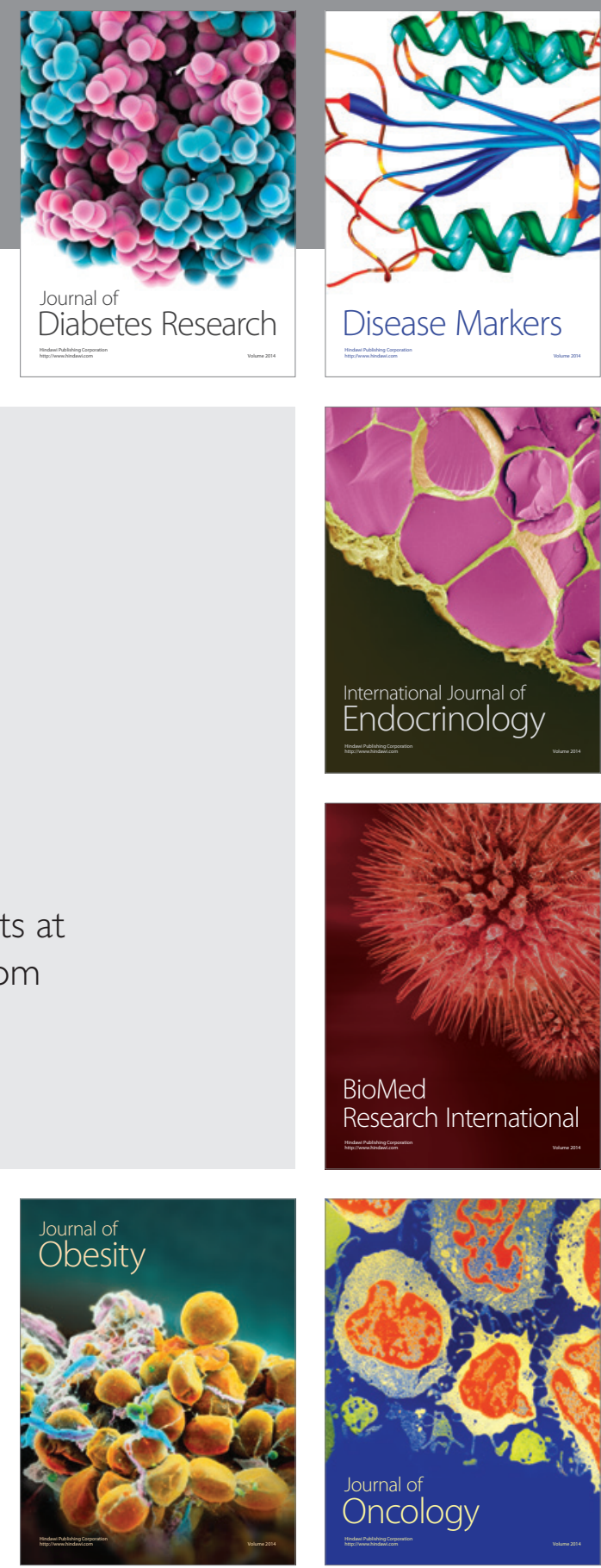

Disease Markers
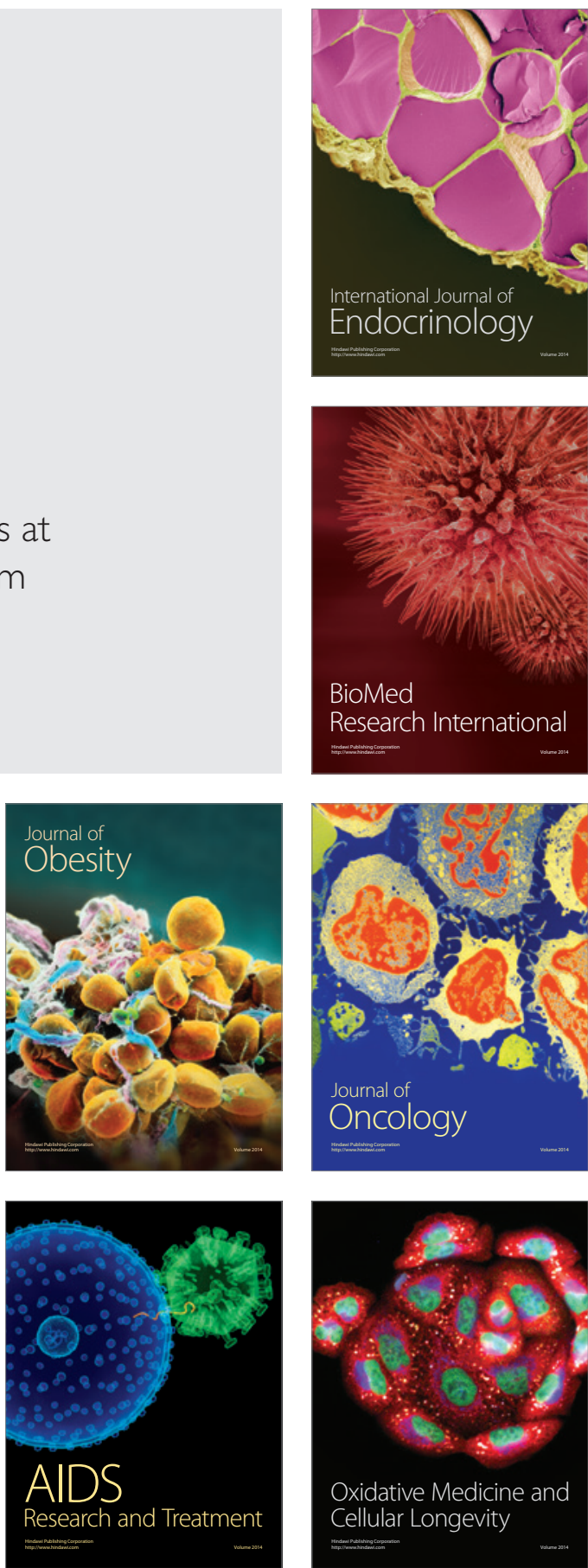